\title{
Precedência malograda: A Rosa Brasileira, o primeiro jornal literário do Rio Grande do Sul?'
}

\author{
Unsuccessful precedence: A Rosa Brasileira, the first literary journal \\ of Rio Grande do Sul?
}

\author{
MAURO NiCOLA PÓvOAS \\ Fundação Universidade Federal do Rio Grande - Rio Grande - Rio Grande do Sul - Brasil
} D

\begin{abstract}
Resumo: O texto aborda a curiosa história de $A$ Rosa Brasileira, que poderia ser considerado o pioneiro periódico literário do Rio Grande do Sul, caso não tivesse sido acusado de plágio ao longo de sua trajetória de apenas três números. O pequeno jornal foi editado na cidade de Rio Grande (RS), em 1851, cinco anos antes, portanto, do semanário O Guaíba (1856-1858), de Porto Alegre, apontando pela crítica como o primeiro periódico sul-rio-grandense dedicado às letras. Empreendimento dirigido por Cândido Augusto de Melo, A Rosa Brasileira circulou nos dias $1^{\circ}$ de março, sábado (n. 1); 30 de março, domingo (n. 2); e 13 de abril, domingo (n. 3), trazendo em suas páginas poemas, artigos, crônicas e anedotas.
\end{abstract}

Palavras-chave: A Rosa Brasileira; Periódicos literários; Literatura Sul-Rio-Grandense

\begin{abstract}
The text covers the curious story of $A$ Rosa Brasileira, which could be considered the pioneer literary periodical of Rio Grande do Sul, had it not been accused of plagiarism over its career of only three numbers. The small journal was published in the city of Rio Grande (RS), in 1851, five years before, therefore, of the weekly publication $O$ Guaiba (1856-1858), from Porto Alegre, pointed by critics as the first journal dedicated to literary writing in the state. Directed by Cândido Augusto de Melo, A Rosa Brasileira circulated on March 1 ${ }^{\text {st }}$, Saturday (n. 1); March $30^{\text {th }}$, Sunday (n. 2); and April $13^{\text {th }}$, Sunday (n. 3), bringing poems, articles, essays and anecdotes in its pages.
\end{abstract}

Keywords: A Rosa Brasileira; Literary magazines; Literature of Rio Grande do Sul

Na Biblioteca Rio-Grandense, da cidade de Rio Grande (RS), é na Sala Silva Paes que se armazenam os livros e os periódicos vinculados ao Rio Grande do Sul. Neste espaço está aquele que pode ser chamado de o primeiro jornal exclusivamente literário do Rio Grande do Sul, A Rosa Brasileira, de 1851. Em geral, atribui-se a O Guaíba o mérito de ser o primeiro periódico dedicado à literatura na então Província. Semanário, $O$ Guaíba circulou em Porto Alegre entre 3 de agosto de 1856 e 26 de dezembro de 1858, num total de 120 números, tendo como editor responsável Carlos Jansen. As páginas da revista traziam matéria literária e não literária; no âmbito da literatura, figuram poemas, contos, novelas e artigos críticos, sob a assinatura de nomes como os de Jansen, João Vespúcio de Abreu e Silva, Miguel Meireles, Félix da Cunha, Rita Barém de Melo, Pedro Antônio

\footnotetext{
Este texto também poderia se chamar: "A história do periódico que
} poderia ter sido, mas não foi”. de Miranda, Inácio de Vasconcelos Ferreira, Frederico Villeroy, Eudoro Berlink e Maria Clemência da Silveira Sampaio, entre outros.

Guilhermino Cesar, na sua História da literatura do Rio Grande do Sul, aponta a importância do periódico porto-alegrense. Dois trechos dão conta dessa inserção fundamental na cronologia literária sul-rio-grandense:

Foi, aliás, com o grupo d'O Guaíba que a literatura rio-grandense começou a tomar forma definida. A contar daí os nossos poetas e escritores apareceram em grupo, unidos por ideais e aspirações comuns, e o seu esforço conjugado, além de marcar fundamente a sua época, revelou, ademais, laços de estreita afinidade com os outros românticos do Centro e do Norte. (CESAR, 1971:153-154)

Morto Antônio José Domingues, tomou-lhe o lugar, como agitador do meio intelectual rio-grandense, seu patrício Antônio Joaquim Dias. Radicando-se primeiramente na cidade de Rio Grande, aí fundou ele 
uma publicação destinada a exercer salutar influência: a Arcádia, que será citada muitas vezes neste trabalho. Apareceu em maio de 1867, quando antes dela só existira na terra gaúcha uma publicação do gênero, O Guaiba. (CESAR, 1971:166-167)²

Obviamente, não se quer aqui retirar a posição consolidada de $O$ Guaíba no cânone dos periódicos do Rio Grande do Sul, por sua duração - três anos, em uma época repleta de jornais efêmeros, é uma boa marca e por seus colaboradores - muitos deles relevantes para o estudo e a compreensão da literatura produzida, naquele momento, no Rio Grande do Sul. Mas pesquisas realizadas na Universidade Federal do Rio Grande (FURG), na esteira dos projetos de pesquisa "O sistema literário rio-grandino no século XIX: estudo sobre a sua formação e consolidação" e "Arquivos, fontes primarias e periódicos", apoiados pelo $\mathrm{CNPq}$, demonstram que a busca em materiais depositados em instituições responsáveis pela sua manutenção e guarda pode lançar novos olhares sobre a historiografia literária consolidada, como é o caso da Rosa.

A Rosa Brasileira teve apenas três edições, circulando em Rio Grande nos dias $1^{\circ}$ de março, sábado (n. 1); 30 de março, domingo (n. 2) e 13 de abril, domingo (n. 3). A periodicidade irregular já apontava para algo que se concretizaria a seguir: a extinção da pequena folha de quatro páginas na terceira edição, totalizando doze páginas. Na verdade, é um jornal que, em tese, não começa e termina nas datas acima apontadas. Empreendimento dirigido por Cândido Augusto de $\mathrm{Melo}^{3}$, dono da tipografia Imparcial, um primeiro negócio na área da imprensa já tinha sido tentado por ele, com $O$ Artilheiro - Folha política e miscelânica, cujo escritório localizavase na Rua Direita, 60, em Rio Grande. O primeiro número que consta da Biblioteca Rio-Grandense é o dois, de 7 de abril de 1849, sendo o último o número 23, de 27 de junho do mesmo ano. Em suas páginas, observa-se a preponderância de temas políticos, como aponta o seu subtítulo, não havendo praticamente textos literários, com exceção de um ou outro poema publicado esparsamente, e algumas anedotas e charadas.

As seguir, Cândido de Melo investe na literatura, por meio de A Rosa Brasileira, ainda na Rua Direita, mas agora no número 75 . Logo depois, sucederam-se

\footnotetext{
2 Athos Damasceno Ferreira, em Imprensa literária de Porto Alegre no século XIX, reafirma o antes dito por Guilhermino Cesar: "O primeiro periódico literário lançado em Porto Alegre - foi também o primeiro do Rio Grande do Sul - data de 3 de agosto de 1856 e denomina-se $O$ Guaíba" (FERREIRA, 1975:13).

3 Português, Cândido Augusto de Melo chegou ao Rio Grande do Sul junto a uma companhia dramática, instalando-se na zona sul do Estado, entre Rio Grande e Pelotas, onde, graças a uma pequena tipografia que o acompanhava, fundou vários jornais: O Rio-Grandense (1845), O Artilheiro (1849), A Rosa Brasileira (1851), A Imprensa (1851) e $O$ Pelotense (1851). Sobre Melo, consultar MARTINS e BANDEIRA.
}

A Imprensa, na mesma rua, n. 173, semanário de quatro páginas que mesclava literatura com notícias, circulando de 30 de abril a 19 de outubro de 1851 , num total de 29 números; e $O$ Pelotense, mudança que teve algum sucesso, pois a terceira tentativa de Melo no periodismo, em 1851, durou até 1855. Para ficar somente no ano aqui estudado, $O$ Pelotense circulou de 7 de novembro a 31 de dezembro, totalizando 22 números, numa periodicidade bastante irregular, pois nesses pouco mais de cinquenta dias de circulação em 1851 teve duas ou quatro páginas, às vezes diariamente, às vezes com duas ou três edições por semana. Ou seja, primeiro, Cândido de Melo transmutou o caráter de suas publicações, de lítero-cultural para noticioso (mudança manifesta nos títulos: A Rosa Brasileira / A Imprensa), depois, tentou a sorte em outro município, indo de Rio Grande para a vizinha Pelotas (A Imprensa / O Pelotense), fundando aí o primeiro periódico pelotense. Todavia, uma análise mais acurada de $A$ Imprensa e $O$ Pelotense fica para outro momento - a ênfase aqui é mesmo A Rosa Brasileira.

Publicado nas três edições, pequeno texto abaixo do título da Rosa indicia alguns elementos importantes para a compreensão da folha, tais como tipografia, localização, periodicidade e escopo:

A Rosa Brasileira, periódico de recreio e instrução, publica-se duas vezes por mês na tipografia de Cândido Augusto de Melo, Rua Direita, n. 75. A assinatura é de 500 rs. por mês pago adiantado. Recebe artigos científicos, que serão publicados gratuitamente.

Embora a expressão "artigos científicos", é o "recreio e instrução" que mais fala sobre as intenções de A Rosa Brasileira, que ficam claras na sua introdução, espécie de "Programa" com as diretrizes do periódico que ora se iniciava, estampado logo na primeira página da edição de $1^{\mathrm{O}}$ de março de 1851 . Ali, o articulista não nomeado começa trazendo uma anedota em torno de Chateaubriand, que sofreu por causa da ignorância de uma princesa da Sardenha, que não identificou naquele com quem conversava o autor que tantas glórias literárias tinha dado à França. Ao trazer a historieta, o autor do texto quer já se desculpar: se nem Chateaubriand conseguiu o reconhecimento pleno, o que dizer do jornal que ora se lançava? É o que diz no seguinte trecho:

Mas sabemos que há zoilos, que, se não por inveja, ao menos (Deus assim os fez para castigo do mundo!) pela impureza e mordacidade de sua alma, acusar-nosão, de nossos primeiros passos não serem de gigante. E, agora lembramo-nos, há neles seu tanto de ignorância e falta de patriotismo. Ignorância por quererem um impossível; falta de patriotismo porque com isto fazem nada menos que sufocar nossa literatura nascente. (A Rosa Brasileira, 1851, n. 1, p. 1) 
Bastante interessante é a referência à "literatura nascente", demonstrando a consciência do responsável pelo texto da importância daquele jornal que ora se iniciava, colaborando com a literatura brasileira, que com a Independência, na esfera política, e o advento do Romantismo, no campo literário, começa a se articular e a se fortalecer. Aliás, no próprio título fica evidenciada a afiliação ao Romantismo, seja na evocação da singeleza, da beleza e do perfume da rosa (cuja ilustração enfeita o cabeçalho), seja na denominação "brasileira", afirmando patrioticamente a sua nacionalidade ${ }^{4}$. Na sequência do texto, por sinal, a questão do nome vem à tona:

Talvez a denominação de nosso periódico seja o alvo dos primeiros tiros dos críticos; mas de caso pensado não daremos razão. Demais se querem um título, espelho do programa do periódico, hão de custar a encontrá-lo, toda a vez que ele for da natureza deste. Todos sabem que a razão das denominações é mais difícil, e, para encurtar polêmicas, diremos por último, que denominamos o nosso periódico assim, porque assim o quisemos, porque assim nos veio à fantasia. (A Rosa Brasileira, 1851, n. 1, p. 1)

Sem aspirar a uma "coroa literária", a esperança é, ao menos, pagando "um tributo à terra que nos viu nascer", deitar uma pedra no "edifício literário brasileiro", à época em plena construção, ou formação, no caminho de Antonio Candido. O texto termina afirmando o papel civilizatório da imprensa, realçando aquilo que estava no frontispício "A Rosa Brasileira é um periódico de recreio e instrução" - e dedicando o trabalho a ser realizado à "mocidade riograndense".

O primeiro número traz ainda em suas páginas poemas e textos variados, todos sem assinatura, até porque a questão da autoria era, na época, pouco valorizada ou relativizada. Há artigos como "A humanidade", "Fases da vida humana" e charadas, além de um pequeno conto, "Ausência", e os poemas "O canto do desterrado", "O desejo", "A flor da saudade", "Queres" e "A vaga". A primeira estrofe de "O canto do desterrado" - trazendo o tema do exílio, tão comum na literatura brasileira desde Gonçalves Dias - diz:

Aqui à beira do mar,

Pensamento despregando,

Transpondo a amplidão do ar,

Deste campo esverdeado,

$\mathrm{Na}$ lira cordas de pranto,

Cobertas de negro manto...

Aqui vem soltar seu canto

$\mathrm{O}$ infeliz desterrado.

(A Rosa Brasileira, 1851, n. 1, p. 3)

\footnotetext{
4 Nesse sentido, o jornal porto-alegrense $O$ Guaiba vai por outro caminho, ao escolher por título o rio que corta a capital gaúcha. Com isso, já afirma um caráter mais localista e menos nacional, embora o dito periódico destaca-se pela inserção no Romantismo brasileiro, não trazendo, por exemplo, nenhum texto que siga o viés regionalista, tão caro à literatura gaúcha.
}

No segundo número, continuam as reflexões em torno da humanidade e das fases da vida humana, iniciadas na edição anterior, e aparecem ainda o texto "A mania de disputar"; uma anedota envolvendo a rivalidade entre portugueses e espanhóis; a resolução da charada do n. 1; e mais um enigma, cuja resposta viria no n. 3, alguns dias depois. Os poemas são "A despedida (Num álbum)", por A., "Liras", por J., e "O beijo da bela" e "Ode", ambas por J. L. C. A., na verdade Joaquim Lopes da Costa Albuquerque. A última quadra de "O beijo da bela" emoldura a temática amorosa que cerca a maioria das produções líricas da Rosa:
E um beijo da bela, ardendo de amor,
De casta paixão
É santo, incendeia, abrasa, arrebata,
Fere um coração.
(A Rosa Brasileira, 1851, n. 2, p. 3-4)

$\mathrm{Na}$ derradeira edição, segue a publicação do texto sobre a humanidade; há, ainda, um "Ao público", assinado por "O proprietário da Rosa Brasileira", e "Governo e lei dos egípcios", de fonte e autoria desconhecidas. Quanto à poesia, L. assina duas composições líricas, "O ciúme" e "Romance"; e Joaquim Albuquerque retorna com "No álbum do Senhor Joaquim Antunes Guimarães", "No álbum de uma senhora" e "No meu álbum", assinando ora J. L. C. A., ora J. L. C. Albuquerque. A reprodução na íntegra de "Romance" serve para a demonstração da constância do temário em torno do amor irrealizado e da saudade da mulher infiel, mesmo que ela tenha destroçado o coração do eu-lírico:

Cruel saudade que oprime Meu terno peito amoroso, Já que desejas qu'eu viva Sempre triste e desgostoso, Deixa que um terno suspiro Eu envie à minha amada, E que ela saiba minh'alma Como vive consternada.

Vai suspiro pressuroso, D'Armia entra no peito Dize-lhe o mal que a saudade, Em minh'alma já tem feito, Dize-lhe que inda vivo Para adorá-la constante E que mesmo ausente dela Sou sempre seu firme amante.

Porém se Armia quebrou $\mathrm{O}$ juramento que deu.

Não fales no meu amor; Ah! volta suspiro meu Não digas quanto a saudade Consome a minha vida, Não, que eu ainda adoro Essa cruel, essa infida. (A Rosa Brasileira, 1851, n. 3, p. 3) 
Os poemas, em geral, sejam os reproduzidos, sejam os apenas citados, não se destacam pela proeminência literária, podendo ser enquadrados no que era escrito e publicado à época. É uma lírica de conteúdo romântico, com um vocabulário e um rigor formal (rimas, métrica, ritmo) típicos, nos passos da poesia que era composta e apreciada no Brasil oitocentista, com marcas de autoria, em geral, bastante tênues e embaçadas 5 .

Agora, o texto mais importante para se pensar $A$ Rosa Brasileira está neste número 3 , de 13 de abril de 1851 - é o "Ao público", que atinge a honra e a capacidade do redator-geral do periódico, que assina muitos dos poemas, Joaquim Albuquerque. Neste "Ao público", o apenas identificado "O proprietário da Rosa Brasileira" (provavelmente Cândido de Melo) vem defender-se das acusações de outra folha da cidade, o Diário do Rio Grande, feitas um mês antes ${ }^{6}$.

A denúncia foi feita nas edições n. 699 ( 8 de março, sábado) e n. 700 (9-10 de março, domingo e segunda-feira) do Diário do Rio Grande, por meio de um "Comunicado", assinado por $\mathrm{O}$ Telescópio, trazendo à tona a farsa montada por Joaquim Lopes da Costa Albuquerque. Em 8 de março, o teor da coluna é o seguinte:

A Tipografia Imparcial imprimiu o primeiro número da Rosa Brasileira, produção de um desses gênios miraculosos que a natureza arroja de séculos em séculos. Hábil piloto, o cultor da Rosa maneja o leme da literatura com assombrosa destridade. $\mathrm{E}$, cousa incrível se não víssemos agora, a Rosa Brasileira verifica a maravilha que se conta de um escritor que no mesmo dia escrevia numa parte do mundo as próprias palavras que noutra parte do mundo publicava outro escritor. O primeiro número da Rosa compõe-se de artigos completos, tais quais

\footnotetext{
5 Como visto, alguns poemas simplesmente não estão assinados; em outros comparecem somente as iniciais: J., L. e A. (todas iniciais de prenome ou sobrenomes de Joaquim Lopes da Costa Albuquerque, o que faz com que se infira ser ele o autor desses poemas todos); há ainda um terceiro grupo composto por J. L. C. A. ou J. L. C. Albuquerque. Descontando-se os poemas não assinados, todos sob suspeição depois das denúncias que serão analisadas a seguir, uma pergunta sobressai-se: foi Albuquerque quem escreveu mesmo os poemas, usando uma ou várias de suas iniciais? De Albuquerque ou não, é possível depreender que são poemas de um mesmo escritor, pela constância e repetição de recursos temáticos, formais e estilísticos; mesmo a musa, Armia, aparece em "Liras", "Ode" e "Romance", conferindo, pelo menos nesse aspecto, uma unidade autoral à produção poética estampada em $A$ Rosa Brasileira.

6 Interessante notar que na segunda edição, de 30 de março, já seria possível a Cândido de Melo trazer a sua defesa, levando-se em consideração que o Diário faz a acusação entre 8 e 10 de março; talvez o jornal já estivesse composto, só sendo lançado nessa data, ou então o silêncio deveu-se a uma tentativa de resgatar os fatos, para ver se eles eram confirmados ou desmentidos. Confirmados, no início de abril vem a retratação, sem que se suspenda o jornal imediatamente, continuando-se a publicação dos textos de Joaquim Albuquerque, provavelmente, de novo, pelo mesmo motivo de antes: o jornal já estaria pronto, e o prejuízo junto aos assinantes seria menor, mesmo trazendo textos de autoria agora controversa. Na verdade, são apenas conjecturas, até porque talvez nunca saibamos da versão de Albuquerque.
}

foram publicados, com imperceptível diferença, no Acadêmico de Pernambuco. Eu cheguei a desconfiar que o cultor da Rosa fosse também Acadêmico algum dia; mas, melhor informado, o homem nem talvez nunca visse essa folha. É um portento, é um aborto. Não cuidem agora que a Rosa não traz nada de casa, que tudo seja furtado: o Telescópio repele tão negra afronta, porque a nada mais atira que a expor à surriada dos moleques um gênio digno de eternas luminárias. Tudo quanto vem na Rosa é de lavra própria; mas admire-se a parecença que tem com os artigos do Acadêmico. (Diário do Rio Grande, 1851, n. 699, p. 1)

O Telescópio usa de um artifício retórico bastante hábil, pois acusa a Rosa de cópia ao mesmo tempo em que se exime da denúncia direta, deixando a constatação ao leitor. Sendo assim, na sequência da página 1 , e pelas páginas 2 e 3 do Diário, sempre em duas colunas, procede-se à comparação de alguns textos - na primeira coluna, o texto da Rosa, na segunda, o do Acadêmico, retirados dos seus números 1 e 2 . São comparados os textos "Introdução", "A humanidade" e "Fases da vida humana"; ao fim, a promessa: "E ainda falta a versalhada, que fica para segunda-feira" (Diário do Rio Grande, 1851, n. 699, p. 3). Realmente, a comparação é mortal para as pretensões dos editores de A Rosa Brasileira em granjear alguma consideração e prestígio: os textos são idênticos, sendo os da Rosa meras cópias do Acadêmico, com pequenos cortes e alterações, como de "mocidade brasileira", no Acadêmico, para "mocidade rio-grandense", na introdução da folha rio-grandina.

$\mathrm{Na}$ edição conjunta dos dias 9 e 10 de março, vem o que fora prometido: "Segue a versalhada da Rosa Brasileira, e o leitor verá se (cousa maravilhosa!) não é tal qual, sem tirar nem pôr, a mesmíssima versalhada do Acadêmico de Pernambuco. Ora, com sua licença:" (Diário do Rio Grande, 1851, n. 700, p. 2). Agora, o alvo é o poema "O canto do desterrado", na Rosa sem autor, e idêntico ao poema publicado no segundo número do Acadêmico, cuja autoria aparece identificada apenas com um A. Após a publicação, em uma única frase $\mathrm{O}$ Telescópio encerra o assunto, irônico: "E então, é bico ou cabeça?" (Diário do Rio Grande, 1851, n. 700, p. 2).

Feita a denúncia, só resta à Rosa as desculpas públicas, o que tenta fazer no número 3. O texto do "Proprietário" começa dizendo que nunca foi "nossa intenção apresentar ao público artigos já publicados em outras folhas". Acusa e culpa pelo ato a Joaquim Lopes da Costa Albuquerque, que possui "pretensões de sábio", mas que "não passa do mais ousado e animoso plagiário", e que vindo de Pernambuco, sua Província natal, procurou a tipografia para propor "uma folha de recreio e instrução, na qual pudesse transmitir ao público todas essas produções que lhe escaldavam a fantasia". O texto aponta que houve 
alguma hesitação em aceder ao pedido de Albuquerque, pois nas cópias por ele trazidas à tipografia havia erros de gramática, regência e ortografia, estranhas em alguém que se denomina "escritor". A incerteza e a insegurança quanto à autoria foram desanuviadas pelo Diário, com o proprietário confessando que ficou "boquiaberto à vista de tão atrevido roubo literário!...”. Ao fim, o texto encerra a fugaz trajetória do periódico:

Acreditando, pois, o Sr. piloto ${ }^{7}$ Joaquim Lopes da Costa Albuquerque destituído da capacidade que inculcara, suspendemos o aparecimento da Rosa Brasileira até que pessoa mais habilitada queira tomar esse encargo. fizemos.

Com o seguinte número termina a assinatura que

Resta-nos, portanto, agradecer àquelas pessoas que, com suas assinaturas, se dignaram coadjuvar uma publicação que poderia tornar-se de algum interesse. (A Rosa Brasileira, 1851, n. 3, p. 1)

O final do trecho trata com lucidez a situação do periódico, ao prever que a Rosa poderia ter ocupado um espaço importante na historiografia literária da Província, no momento em que foi a primeira publicação prioritariamente destinada à poesia e aos escritos filosófico-existenciais no Rio Grande do Sul.

Dezessete dias depois, em 30 de abril de 1851, uma quarta-feira, na primeira página do primeiro número do novo jornal, A Imprensa - que obviamente apresentase com outro título, na intenção de fugir da má-fama adquirida pelo antecessor -, o proprietário (Cândido de Melo, como sempre sem assinar) traz outro "Ao público", em que aponta que apareceu a "pessoa habilitada" por ele requisitada na última edição de $A$ Rosa Brasileira: no novo periódico, a parte literária caberá à "Ilma. Sra. D. Joana Paula Mansos Noronha, cujos escritos são conhecidos por muitas pessoas no Rio Grande”. Esperavase que a vida do novo periódico não seja "monótona, árida e de esterilidade", como se deu com a Rosa, mas "de animação, de esperanças, e de interesse para todas as classes de leitores", em especial para o "sexo amável", pois é "sem dúvida a primeira vez que, entre nós, uma senhora se encarrega do penoso trabalho de redigir um periódico; isto mesmo é de bom agouro para nós". (A Imprensa, 1851, n. 1, p. 1)

Realmente, a imprensa feminina, que se tornaria comum ao longo da segunda metade do século XIX no Brasil, ainda era ausente no Rio Grande do Sul. Coincidência ou não, a tímida iniciativa feminista de Cândido de Melo e Joana Noronha deu-se na mesma

\footnotetext{
Interessante notar que o Diário refere-se a Albuquerque, irônica e pejorativamente, como o "piloto", epíteto assumido pela Rosa, como que se coadunando com as denúncias feitas.
}

cidade que anos depois seria o berço do Corimbo, das irmãs Revocata Heloísa de Melo e Julieta de Melo Monteiro, longevo periódico de Rio Grande dedicado às mulheres - circulou durante sessenta anos, de 1883 a 1943.

Ao fim do "Ao público", informa-se que o primeiro número de $A$ Imprensa ainda publica os dois últimos textos trazidos à redação pelo "piloto" Albuquerque: "A humanidade" e "O pranto do abandonado". Em especial, o primeiro é publicado em respeito aos leitores, para que não perdessem a sequência final de um artigo que tinha sido publicado ao longo dos três números de $A$ Rosa Brasileira.

As matérias que interessavam ao novo jornal eram principalmente a literatura, o comércio, os anúncios e as variedades. Um "Programa", na p. 2 do n. 1, aponta que o jornal falará "de literatura romântica, ao público sentimentalista; é dizer, a esse público jovem, elegante, gracioso, que se compõe de moças bonitas, e de rapazes do estilo Lord Byron". Além da literatura, trará modas, teatro, crônicas, bailes, "essa imensa multidão de nadas brilhantes". Convém notar que o nome do novo periódico traz consigo a evocação da liberdade de pensamento preconizada pela ação da imprensa no século XIX, o que de certa forma está inscrito no jogo estabelecido entre os nomes das duas empresas:

A Imprensa, sucessora da Rosa Brasileira, não pode ter a elegante fragrância desta; porém em troco, sua existência não é frágil e transitória como o foi a da mimosa flor que, plantada por mão rude, cedo morreu ao desabrochar. A Imprensa, longe disso, simboliza a civilização, e essa gigante alavanca que dando vida aos pensamentos, e ensinando aos povos as ciências, serviu até agora de alicerce à civilização moderna, é duradoura como necessidade vital das nações. Assim, orgulhosos do nome da nossa folha, empregaremos em sustentá-la toda a força da nossa vontade, e aquela faísca de inteligência com que Deus iluminou a mente de toda criatura. (A Imprensa, 1851, n. 1, p. 2)

O curioso é que o Diário do Rio Grande, o responsável pela denúncia que levou à derrocada de $A$ Rosa Brasileira, em 1 de maio de 1851, portanto um dia após o primeiro número de $A$ Imprensa vir a lume, comenta o surgimento do novo órgão jornalístico em suas páginas:

Publicou-se ontem o primeiro número da $\mathrm{Im}$ prensa, periódico de recreio, instrução e de notícias, impresso uma vez por semana na tipografia Imparcial.

A parte literária da Imprensa, que vem substituir a Rosa Brasileira, está confiada à Ilma. Sra. D. Joana Paulo Mansos Noronha. (Diário do Rio Grande, 1851, n. 739, p. 3 ) 
Do que foi visto, fica a constatação de que $A$ Rosa Brasileira não se constituiu como um empreendimento de um grupo mais ou menos coeso e consciente de suas atitudes e atribuições, como se dará com $O$ Guaíba, cinco anos depois. Foi, na verdade, fruto de uma ação individual - um pretenso poeta, provavelmente recém-chegado à cidade, procura um tipógrafo que já tinha editado um jornal, sem sucesso. Junta-se, assim, o par ideal: de um lado, o escritor, o presumível dono das ideias e do talento, aquele que tem algo a dizer; de outro, o empresário, aquele que detém os modos de produção e possibilitará, com seu maquinário e infraestrutura, a editoração, a impressão e a distribuição do jornal, permitindo o ganho financeiro com o seu aparato gráfico, novidade na cidade. Como fica claro no texto introdutório de $A$ Imprensa, Cândido de Melo tinha todo o interesse em dar uso à sua tipografia, e o surgimento de uma mulher permite que o sonho, o desejo e a pretensão de possuir um jornal continuasse, não mais apenas de recreio, instrução e literário, mas também, agora, noticioso.

Com efeito, se A Rosa Brasileira foi a primeira tentativa de periódico literário na Província sulina, tal iniciativa foi malograda pela descoberta do plágio, o que colaborou na ausência de comentários críticohistoriográficos sobre a existência do jornal. A cópia descarada de textos de um congênere pernambucano, ao mesmo tempo em que excluiu e obnubilou o periódico, inviabilizou-o comercialmente, no momento em que o descrédito recaiu sob a iniciativa, o que levou Melo a trocar sucessivas vezes o nome e o caráter de seus empreendimentos ao longo de 1851, conforme já visto.

Sobre a figura de Cândido Augusto de Melo, aliás, em aceitando a sua inocência no caso de contrafação, recai certa simpatia por quem estuda literatura. Conforme se lê no seu pedido de desculpas ao público, observa-se que o tipógrafo e empresário acreditou e investiu num mercado que era, ainda, incipiente para o consumo e a fruição da literatura, atitude que configura uma vontade de discutir e divulgar poemas, contos e artigos científicos, mesmo que, obviamente, houvesse, por trás desse movimento, o interesse monetário.

Delineiam-se, por fim, algumas vias, que podem ser encaradas como possíveis, embora inconclusas, em torno da repercussão do jornal e sobre a questão da autoria, em especial os motivos pelos quais A Rosa Brasileira foi subsumida da história da literatura sul-rio-grandense, sem que nenhum crítico a citasse desde o seu surgimento em 1ํ de março de 1851. Quatro hipóteses iniciais podem ser aventadas:

1. devido à baixa qualidade estética de seus poemas, embora, levando em conta a preponderância histórica de um jornal estritamente literário na Província, isso até pudesse ser relativizado;
2. por causa das poucas edições - três - existentes e aos poucos colaboradores, que não formam uma continuidade e não dão uma ideia de conjunto, elementos decisivos no estabelecimento de um periódico junto ao público;

3. o fato de ele estar depositado apenas na Biblioteca Rio-Grandense, em volume de tamanho médio, arquivado em meio a alguns outros jornais, o que dificulta a sua descoberta e pesquisa;

4. a pirataria editorial de Albuquerque, a princípio inocente e ingenuamente acatada por Melo, o que desacreditou o jornal, jogando-o num limbo.

Talvez a explicação passe por uma mescla de todos esses quatro itens, com o último se revestindo de maior relevância, embora a questão da autoria fosse pouco respeitada. No entanto, evidencia-se que copiar algo sem a permissão ou a explicitação do verdadeiro autor, mesmo em época de poucos cuidados com a reprodução consentida, era uma contravenção que poderia desonrar o empreendimento no seu nascedouro. Tanto assim, que Cândido de Melo escusa-se da cópia descoberta pelo Diário do Rio Grande, dizendo que bastava ter colocado nas páginas da Rosa a palavra "Extraído", procedimento comum no século XIX:

Não, repetimos, para publicar o que é de outrem, não precisávamos que o Sr. piloto Albuquerque viesse lá da sua Província manejar o leme da plagiatura; nós mesmos, escrevendo por baixo dos artigos a declaração - Extraído - ou citando os nomes de seus autores, teríamos preenchido esse encargo. (A Rosa Brasileira, 1851, n. 3, p. 1)

Deste modo, seria resolvida a questão da cópia indigna, mas ainda não se saberia o nome do autor nem a fonte de onde fora retirado o texto - até porque não havia dinheiro para pagar pelo texto e uma lei de direitos autorais ainda era uma utopia. Mas será que ao menos a colocação de "Extraído" ao fim dos textos copiados salvaria a Rosa do malogro, do descrédito e do esquecimento, causados pelo episódio que tão mal repercutiu na imprensa e na sociedade locais? A pergunta, sabe-se, é retórica e irrespondível, o que faz com que permaneça a interrogação.

\section{Referências}

A Imprensa. Rio Grande, 30 abr. 1851-19 out. 1851.

A Rosa Brasileira. Rio Grande, 1ํ mar. 1851-13 abr. 1851.

BANDEIRA, Gisele Pereira. O comércio rio-grandino de livros em 1855. In: PÓVOAS, Mauro Nicola; VAZ, Artur Emilio Alarcon (Org.). Anais do $3^{\circ}$ Encontro Nacional de Pesquisadores em Periódicos Literários Brasileiros. Rio Grande: FURG, 2010, p. 264-271. CD-ROM. 
CESAR, Guilhermino. História da literatura do Rio Grande do Sul. Porto Alegre: Globo, 1971.

Diário de Rio Grande - Folha comercial e política. Rio Grande, 8 mar. 1851; 9-10 mar. 1851.

FERREIRA, Athos Damasceno. Imprensa literária de Porto Alegre no século XIX. Porto Alegre: Ed. da UFRGS, 1975.

MARTINS, Ari. Escritores do Rio Grande do Sul. Porto Alegre: Ed. da UFRGS/IEL, 1978.

O Artilheiro - Folha política e miscelânica. Rio Grande, 7 abr. 1849-27 jun. 1849.
O Pelotense. Pelotas, 7 nov. 1851-31 dez. 1851.

VALENTE, Joana Mieres. O homem, a humanidade e o amor n'A Rosa Brasileira (1851). In: PÓVOAS, Mauro Nicola; VAZ, Artur Emilio Alarcon (Org.). Anais do $3^{\circ}$ Encontro Nacional de Pesquisadores em Periódicos Literários Brasileiros. Rio Grande: FURG, 2010. p. 323-335. CD-ROM.

Recebido: 08 de setembro de 2014 Aprovado: 19 de janeiro de 2015 Contato:mnpovoas@cpovo.net 